\title{
TEXT TABLES
}

1 Area Units Descriptive of London 4

2 The London Boroughs and Their Former Status 34

3 The Initial Division of Functions Between the Greater London Council $\begin{array}{ll}\text { and the New London Boroughs } & \mathbf{4 0}\end{array}$

4 The Size of the Lower-Tier Units: Redcliffe-Maud Commission Recommendations and the Greater London Reorganization 146

5 Allocation of Services in Large Metropolitan Areas: Redcliffe-Maud Commission Proposal

6 Allocation of Services in Scotland: Wheatley Commission Proposal 154

7 Allocation of Functions in England: Conservative Government Proposal, February 1971

\section{MAPS}

1 Component Areas of the London Region 2

2 London Metropolitan Greenbelt and New Towns 3

3 Former Local Governments within the Area to Become Greater London 29

4 London Boroughs in Inner and Outer London 37

5 Political Majorities in the Greater London Council, by London Boroughs, 1964-1970

6 Areas Proposed for Expansion in "The South East Study" 85

7 Development Strategy Proposed by the South East Economic Planning Council

8 Proposed London Motorway Scheme

\section{APPENDIX TABLES}

I Employment in Greater London, the London Metropolitan Region, the South East Region, and England and Wales, 1951-1966

II Industrial Composition of Increased Employment in Greater London, the South East Region, and England and Wales, 1961-1966

III Population of London, the London Region, the South East Region, and England and Wales, 1931-1981

IV Household Spaces by Tenure and Management, Inner and Outer London, 1966 